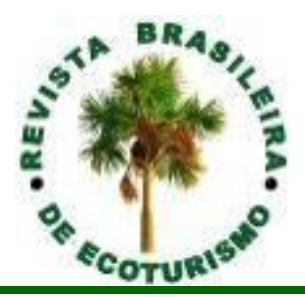

\title{
Educação e interpretação ambiental como ferramenta de implantação do ecoturismo na Área de Proteção Ambiental da Serra de Baturité (CE)
}

\section{Environmental education and interpretation as ecotourism deployment tool in the Environmental Protection Area of the "Serra de Baturité" (CE, Brazil)}

\section{Hermógenes Henrique Oliveira Nascimento}

\begin{abstract}
RESUMO
Por uma nova dinâmica de gestão territorial baseada de forma interdisciplinar e integrada com as vocações locais de destinos turísticos, o trabalho em questão se justifica pela importância de preservar e valorizar ecossistemas endêmicos, principalmente, os remanescentes do bioma de Mata Atlântica, como também áreas de recursos hídricos através do ecoturismo. Com esse enfoque estratégico, o objetivo central deste estudo é verificar se a implantação de uma gestão ambiental sistêmica se fortalece na medida em que as ferramentas da educação e interpretação ambiental se apresentam como transversais no planejamento de políticas públicas para o desenvolvimento da atividade do ecoturismo na APA da Serra de Baturité (compreendida pelos municípios de Aratuba, Mulungu, Guaramiranga, Pacoti e Redenção - CE). Logo, dar-se ênfase a esse trabalho, na medida em que projetos que valorizam a implantação de atividades ecoturísticas ou associadas ao tema têm demonstrado contribuir com relevância para conscientizar a população sobre a importância de se preservar, conservar e recuperar áreas de grande valor ambiental e social.
\end{abstract}

PALAVRAS-CHAVE: Educação Ambiental; Ecoturismo; Gestão.

\begin{abstract}
For a new dynamic of territorial management based interdisciplinary and integrated with local vocations of tourist destinations, the work in question is justified by the importance of preserving and enhancing endemic ecosystems, mainly the remnants of the biome of the Atlantic Forest, as well as areas water resources through ecotourism. With this strategic focus, the central objective of this study is to verify that the implementation of a systematic environmental management is strengthened to the extent that the tools of environmental education and interpretation are presented as cross in the planning of public policies for the development of ecotourism activity EPA of "Serra de Baturité" (comprised by the municipalities of Aratuba, Mulungu, Guaramiranga, Pacoti and Redenção - CE, Brazil). So if give emphasis to this work, to the extent that projects emphasizing the implementation of ecotourism activities or associated with the topic have shown to contribute relevant to raise awareness about the importance of conservation, preservation and restoration of areas of great environmental value and social.
\end{abstract}

KEYWORDS: Environmental Education; Ecotourism; Management. 


\title{
Introdução
}

A perda da biodiversidade é um fato incontestável e vem se agravando a cada dia com mais intensidade. A destruição de ecossistemas e a consequente extinção de espécies da flora e da fauna constituem-se em um grave e irreversível problema. Nesses casos, cabe ao ser humano utilizar-se de alternativas que propicie a preservação do meio ambiente em condições de equilíbrio. Que depende, por sua vez, da conservação dos ecossistemas, associado a estratégicas que vise o controle dos impactos das ações do ser humano. O estabelecimento de áreas protegidas visa, dentre vários objetivos, a proteção à biodiversidade.

Diante disso, a Educação Ambiental visa desenvolver a consciência da sociedade em escala mundial, com relação ao meio. A educação é considerada como atividade de grande relevância para a efetividade da gestão em Unidades de Conservação (UC), uma vez que contribua para o desenvolvimento da consciência ecológica dos frequentadores, o que diminuirá os riscos de degradação dos recursos naturais no futuro. A atividade de Educação Ambiental visa não só sensibilizar os visitantes e comunidades quanto à importância da conservação do meio ambiente e do desenvolvimento sustentável, mas também fornecer ferramentas para que tais atividades venham a ser incorporadas pelas comunidades que coexistem com as UC.

Conforme Dias (2004) Patrick Geddes, escocês, considerado o "pai da Educação Ambiental", já expressava a sua preocupação com os efeitos da Revolução Industrial, iniciada em 1779, na Inglaterra, pelo desenvolvimento do processo de urbanização e suas consequências para o meio ambiente natural. Segundo Sato (apud Jansen, Vieira e Kraisch, 2007) a Conferência de Tbilisi definiu o conceito de Educação Ambiental:

\begin{abstract}
A Educação Ambiental é um processo de reconhecimento de valores e clarificação de conceitos, objetivando o desenvolvimento das habilidades e modificando as atitudes em relação ao meio, para entender e apreciar as interrelações entre os seres humanos suas culturas e seus meios biofísicos. A Educação Ambiental também está relacionada com a prática das tomadas de decisões e a ética que conduzem para a melhoria da qualidade de vida.
\end{abstract}

De acordo com o conceito proposto pela Conferência de Tbilisi, é perceptível que a Educação Ambiental (EA) é um processo que deve ser contínuo. Uma vez que, o objetivo da mesma, é justamente proporcionar o desenvolvimento de hábitos, atitudes e conhecimentos que levem a uma mudança tanto de posicionamento quanto de comportamento, por parte dos cidadãos.

Em 1987, houve a publicação do Relatório de Brundtland (Nosso Futuro Comum) que institui o conceito de desenvolvimento sustentável. Em 1992, aconteceu no Rio de Janeiro, Brasil, a ECO 92, cujo objetivo era promover o debate ambiental e buscar estratégias para o desenvolvimento 
sustentável. Durante o evento houve a assinatura da Agenda 21, documento que estabelecia metas para a melhoria das condições ambientais do planeta.

O Brasil é o único país da América Latina que tem uma Política Nacional direcionada a Educação Ambiental. Pode-se dizer que essa foi uma grande conquista política, porém, devido às discussões terem iniciado de forma tardia no país, a Educação Ambiental na sua execução apresenta grandes dificuldades.

Para Pedrini (1997) "O que causa a degradação ambiental é, dentre outros motivos, a falta de Educação Ambiental".

Logo, a EA conduz ao uso racional dos recursos naturais, por parte dos homens. É necessário conhecer o meio ambiente e as relações existentes no mesmo, só assim o homem poderá defendê-lo. Para Minimi (2000 apud DIAS, 2004):
A Educação Ambiental é um processo que consiste em propiciar as pessoas uma compreensão crítica e global do ambiente, para elucidar valores e desenvolver atitudes que Ihes permitam adotar uma posição consciente e participativa, a respeito das questões relacionadas com a conservação e adequada utilização dos recursos naturais, para a melhoria da qualidade de vida e a eliminação da pobreza extrema e do consumismo desenfreado.

Sob a ótica do nosso objeto de estudo (Figura 1, próxima página), a Área de Proteção Ambiental (APA) da Serra de Baturité conta com 32.690 hectares de superfície e foi criada através do Decreto Estadual n 20.956, de 18 de Setembro de 1990. Localizada no Norte do Estado, na região serrana do Maciço de Baturité, a 104Km de Fortaleza. O ecossistema é considerado de "serra úmida". O Maciço de Baturité é um ecossistema paradisíaco onde se encontra um dos poucos vestígios de Mata Atlântica ainda existente no interior do nordeste. O nome Baturité significa "serra verdadeira" no idioma dos tupis, habitantes originais da região.

Ao aprofundar a temática sobre sustentabilidade dos recursos naturais, verifica-se que um fator importante para o sucesso na implementação do ecoturismo em UC e, principalmente, na APA da Serra de Baturité é a participação e inclusão da população residente e do entorno dessas áreas em todo o processo, criando o sentimento de pertencimento para com a área, capaz de contribuir na conservação, e de apoderamento das relações socioeconômicas que dizem respeito à atividade turística. 


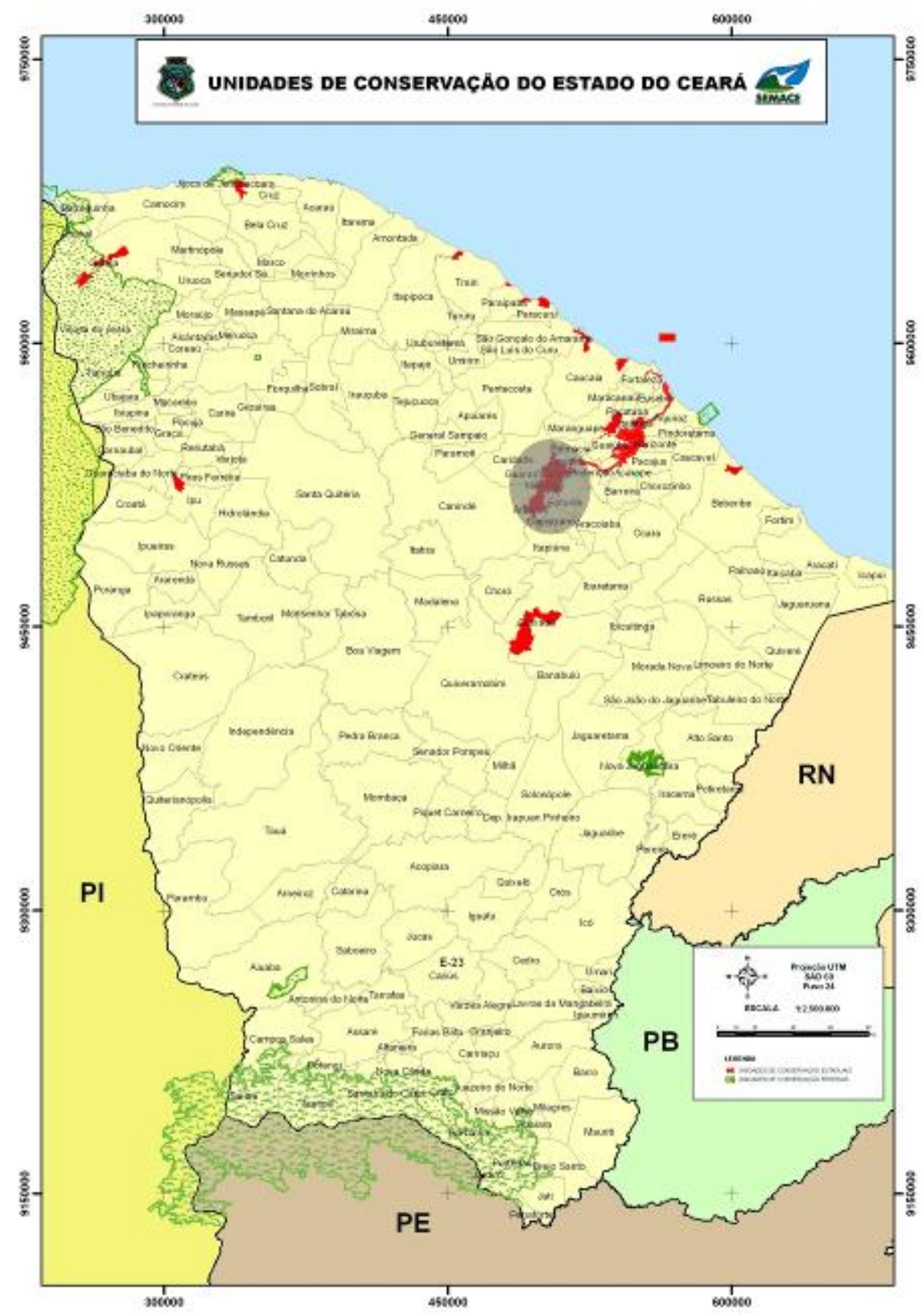

Figura 1: Unidades de Conservação, com destaque para a APA de Baturité. Figure 1: Protects Areas, with emphasis on the APA Baturité.

Fonte: Adaptado de SEMACE (2014).

Source: Adapted from SEMACE (2014).

Neste contexto, às Unidades de Conservação cabem papéis significativos quando buscam proteger espaços territoriais criados pelo poder público, delimitados com o objetivo de assegurar a conservação de seus recursos ambientais, possuindo características naturais relevantes, sendo submetidos a um regime especial de administração e adequada proteção. Assim sendo, o turismo em áreas naturais, consequentemente, foi um incentivador e, ao mesmo tempo, incentivado pelos movimentos da criação 
das primeiras UC. Isso porque, os padrões de importância na criação de áreas protegidas fundamentavam-se muito mais na questão da socialização, no usufruto da população das belezas cênicas desses lugares do que na própria importância de respeito e conservação às demais formas de vida.

A história da conservação ambiental no Ceará iniciou-se com o Decreto-lei 9.226, de 02 de junho de 1946, que criou a primeira unidade de conservação federal no Estado, a Floresta Nacional do Araripe. Atualmente o Estado conta com vinte e quatro áreas de UC.

Compreende-se assim que estimular a gestão das Unidades de Conservação, criar mecanismos de preservação de ambientes frágeis e incentivar a sustentabilidade no uso de seus recursos é o desafio assumido pelo governo em resposta aos anseios do povo cearense. Nesse contexto, o belo, o singular, o exótico aparece como incentivo ao sentimento de se contemplar e valorizar o que é do cearense, propiciar aos diferentes olhares o conhecer, o sentir para agir e conservar, contribuindo, desse modo para o desenvolvimento da educação e interpretação ambiental na APA da Serra de Baturité.

Como se vê, diante dos grandes desafios que acometem a civilização cearense neste princípio de terceiro milênio, a discussão em torno dos rumos a serem tomados no trato das questões ambientais assume posição de destaque. Nunca esteve tão em pauta a preocupação com a preservação dos recursos naturais do Estado, em suas mais variadas formas, e com o aprimoramento dos meios necessários à manutenção do patrimônio natural e cultural.

Observa-se com o desenrolar da pesquisa, um maior envolvimento da comunidade inserida na APA a respeito da definição dos princípios que devem reger o seu relacionamento com a natureza que a cerca.

\section{A educação e interpretação ambiental em prol do ecoturismo em Unidades de Conservação: um olhar sobre a APA da Serra de Baturité}

O Sistema Nacional de Unidades de Conservação (SNUC), instituído pela lei no 9.985 de 2000, estabelece que as UC são áreas instituídas com o objetivo de preservação e/ou conservação da natureza, dependendo de sua categoria. Isso quer dizer que são áreas estabelecidas para a manutenção ecológica, para a preservação da biodiversidade e para a utilização sustentada das espécies e do ecossistema, o que pode ocorrer juntamente com a atividade turística, por exemplo, favorecendo e incentivando 0 desenvolvimento da EA e o manejo adequado dos recursos naturais.

Verifica-se que o SNUC é atualmente o quarto maior sistema de Unidades de Conservação do mundo. Ele abrange cerca de 1,4 milhões de $\mathrm{km}^{2}$ ou em torno de 15\% do território nacional. Entre 2003 e 2008 houve um rápido aumento do número de áreas protegidas. Essa ampliação corresponde a $75 \%$ de todas as Unidades de Conservação criadas no mundo nesse período. Apesar disso, o Brasil ainda não alcançou as Metas de Aichi da Convenção sobre Biodiversidade e muitas de suas unidades de 
conservação não estão efetivamente protegidas. A despeito de empenho próprio e do apoio da cooperação internacional, a parte não coberta da demanda por investimentos é estimada atualmente em 1 bilhão de dólares. Para operação, manutenção e administração seria necessária uma quantia adicional de aproximadamente 500 milhões de dólares por ano.

O SNUC trata também de diretrizes que asseguram a participação efetiva das populações locais na criação, na implementação e na gestão das UC, além da realização de práticas de EA, e condução das atividades de lazer e do ecoturismo.

O IBAMA (2002) aponta a Educação Ambiental como interessante alternativa de sensibilizar as pessoas para participar na elaboração e execução de políticas públicas, a Educação Ambiental neste caso traria um senso crítico sobre o que se está se passando e instigá-las-ia a proporem as ações cabíveis ao campo de ação delas, já que é de interesse de todos a preservação da natureza para as futuras e presentes gerações.

Para que o convívio das pessoas com o ambiente seja harmonioso e que contribuam na conservação, é necessária à Educação Ambiental, pois de acordo com Antunes, Coelho e Jochem (2006) ao realizá-la estaríamos promovendo a interação harmônica entre o ser humano visando estabelecer laços de respeito e cooperação entre as UC e comunidades do entorno.

Brugger (2004), fala sobre como deve ser feita a Educação Ambiental, a autora cria uma crítica aos atuais métodos de ensino, no qual a pessoa estaria sendo levada a executar determinadas funções como um treinamento ou adestramento.

Ainda segundo a autora é importante estimular a criatividade e o pensamento das pessoas ao invés de ensinar determinadas funções, porque assim ela estaria criando pensadores, ao invés de alienados, e partiriam deles a solução para os problemas ambientais. Para que tal situação ocorra, a Educação Ambiental deve levar informação de conteúdo interdisciplinar ligados ao cotidiano, numa linguagem adequada, absorvendo assim a relação entre o homem e a natureza e não se prendam as visões dominantes de tecnologia.

Oliveira (2010) e Frey (2001) alegam que a problemática ambiental coloca em discussão a relação sociedade-natureza e a falta de atuação dos atores sociais, (prefeitos, administradores, políticos) tanto no nível local, nacional ou internacional onde não tem conseguido traduzir as crescentes demandas ambientais em políticas públicas, políticas estas que sejam capazes de promover esse modelo alternativo de desenvolvimento.

Deve-se ter consciência que UC é um termo muito amplo no qual estaremos lidando com vários grupos de pessoas com diferentes formas de pensar. Precisa-se então de articular formas - métodos para conversar/articular com diferentes sujeitos. Por exemplo, as áreas destinadas aos visitantes necessitam de uma abordagem educacional diferente daquela proposta pela comunidade de entorno. Cada UC é um estudo de caso, provavelmente a Educação Ambiental nestes lugares terá resultados muito distintos. 
Em vista dos benefícios da Educação Ambiental e suas diferentes abordagens, têm sido desenvolvidos projetos de Educação Ambiental como cursos, palestras e mutirões na APA da Serra de Baturité em busca da sustentabilidade, por meio da sensibilização da comunidade

No caso da referida APA, constata-se que as ações em prol do desenvolvimento do ecoturismo por meio da Educação Ambiental (Figura 2), ainda é incipiente, necessitando sobremaneira de políticas públicas efetivas que consolidem a atividade turística sob a ótica ambiental, econômica, social e cultural.

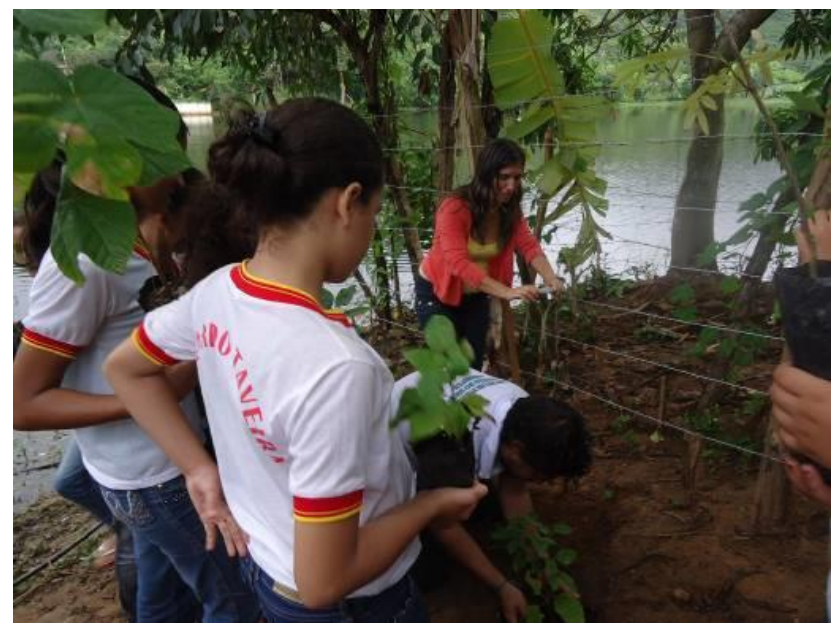

Figura 2: Ação de Educação Ambiental com estudantes.

Figure 2: Action of Environmental Education with students

Fonte: Hermógenes Henrique Oliveira Nascimento (2014).

Source: Hermógenes Henrique Oliveira Nascimento (2014).

Cabe, portanto, investigar possibilidades e desafios para a implementação do ecoturismo na APA, baseando-se na concepção da interpretação ambiental que possa levar à compreensão da importância do patrimônio ambiental e cultural. Ressalta-se também a relevância de averiguar o potencial e as vocações naturais dos territórios que compreendem a APA, bem como os fatores limitantes encontrados, devendo também analisar as demandas locais e regionais para um efetivo desenvolvimento da atividade ecoturística.

\section{O resgate histórico da APA e sua contribuição para o ecoturismo}

A Região Nordeste do Brasil, mais especificamente no Estado do Ceará, as paisagens de exceção, segundo Ab'Sáber (2003), verificam-se ao longo de seu território, exemplificadas pelos: agrupamentos de inselbergs, sob a forma de "montes ou ilhas" rochosas que pontilham domínios das caatingas; e maciços elevados, voltados para os ventos úmidos vindos do Oceano Atlântico, resultando na formação de florestas tropicais de cimeira, também denominados como "enclaves", "encraves " ou "ilhas" úmidas, que se apresentam dispostos em pleno sertões secos. 
Os maciços elevados cearenses, mas conhecidos por serras, têm importância fundamental por comporem um sistema de dispersão de drenagem. Dentre estes, a Serra de Baturité é o de maior expressividade, onde ainda é possível identificar resquícios da Mata Atlântica (Figura 3).

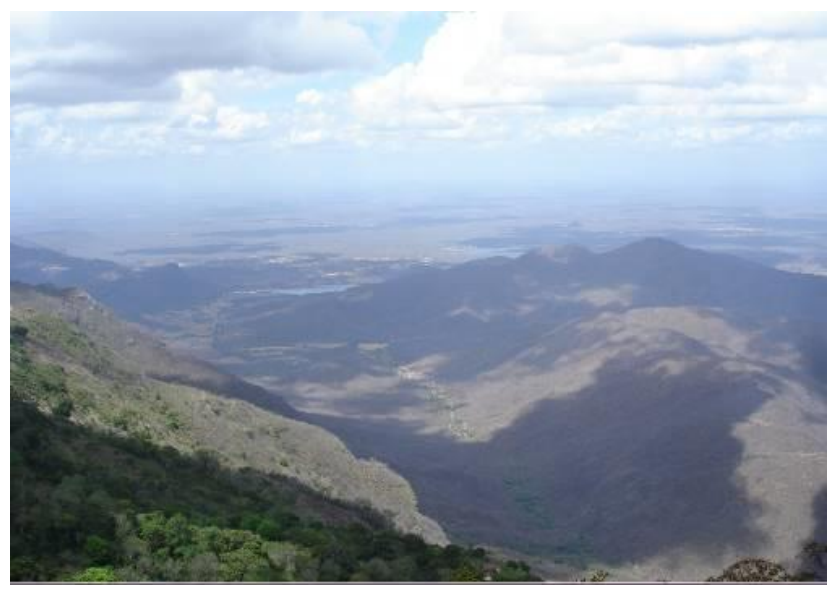

Figura 3: Maciço de Baturité com seus enclaves.

Figure 3: Massif of Baturité.

Fonte: Hermógenes Henrique Oliveira Nascimento (2014).

Source: Hermógenes Henrique Oliveira Nascimento (2014).

A exuberância paisagística da Serra de Baturité justifica-se pelo comportamento de um ambiente diferenciado, onde a altitude do relevo possibilita a existência de condições climáticas que potencializam, favoravelmente, a ocorrência de um enclave de mata úmida, no domínio semiárido das caatingas, com formação influenciada pelos ventos que sopram do Oceano Atlântico. As potencialidades dos recursos naturais favorecem, historicamente, a criação de condições propícias ao desempenho das atividades agrícolas e da fixação de populações.

Assim, desde que começou a ser ocupada, por volta do século XVIII, iniciaram-se processos de exploração intensa, sob os quais a mata, ali existente, ia sendo continuamente retirada para dar lugar a espaços urbanos e áreas agrícolas, sem qualquer limite.

É interessante destacar o fato de que a ocupação da Serra de Baturité, bem como de outras regiões serranas do Estado ocorreu de forma singular, em virtude das características topográficas, que dificultavam 0 acesso pela declividade das vertentes, e das características geoambientais (bem como condições climáticas favoráveis, recursos hídricos, fertilidade e profundidade dos solos) que, atrativas, propiciavam o desenvolvimento de outras atividades.

Dessa forma, foi necessário instituir medidas para conter os efeitos negativos causados pelo uso e pela ocupação da terra, na Serra, mediante aplicação de instrumentos normativos com objetivos claros e práticos de uso sustentável, buscando-se uma forma de concretizar uma relação harmoniosa entre a sociedade e a natureza e, assim, procurar manter vivo o que ainda resta da biodiversidade local. Dentre as possibilidades viáveis para deter o uso desordenado dos recursos naturais, em desacordo com as prescrições 
legalmente estabelecidas, criou-se uma Unidade de Conservação: a Área de Proteção Ambiental (APA) da Serra de Baturité.

O conjunto das cidades que compõem 0 Maciço, mais especificamente, os da APA da Serra de Baturité, portanto, mesmo se consolidando no século XIX, tem origens que remontam ao século XVII. São vários sítios urbanos, vilas e distritos com referências à época em que a região foi colonizada, referências de grande importância quanto às tradições e patrimônio histórico, já que os mesmos estão entre as configurações urbanas mais antigas e tradicionais do Estado do Ceará.

Estes aspectos da representatividade do patrimônio histórico e cultural apontam para sua relevância e nos forçam a reconhecer que o passado do Maciço foi mais expressivo, do ponto de vista econômico, do que é o seu presente. Esta constatação abre espaço para identificar neste passado, um contexto abrangente de cenários construídos a preservar e desenvolver à atividade ecoturística, tais como: fazendas e sítios de café, edificações coloniais (Figura 4), estações ferroviárias e mercados antigos sequência de espaços urbanos construídos de forma vernacular, notadamente situações serranas - por conta de sua topografia acidentada.

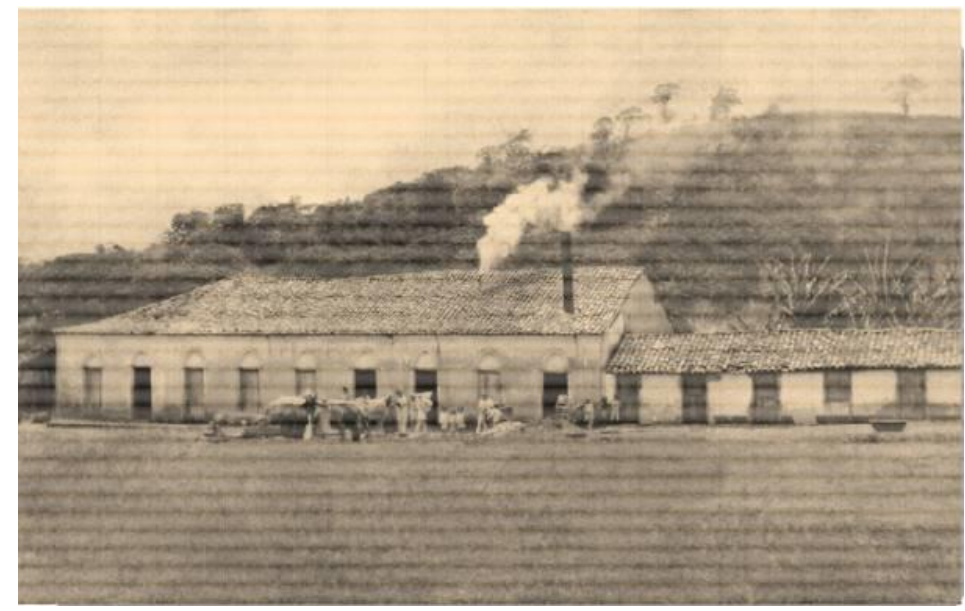

Figura 4: Fábrica de beneficiar café em Guaramiranga. Figure 4: Factory to benefit coffee in Guaramiranga.

Fonte: Museu da fotografia de Guaramiranga (2014).

Source: Photography Museum of Guaramiranga (2014).

O resgate da imagem construída do Maciço seja associado às inúmeras expressões da paisagem natural, cuja beleza e especificidade impõem proteger e conservar e às diversificadas manifestações culturais dos municípios da APA, vislumbra-se um outro conjunto expressivo de elementos capazes de gerar para a região, um vetor econômico de desenvolvimento, estreitamente associado ao ecoturismo decorrente das potencialidades do clima, da natureza e das manifestações culturais da região.

No entanto, a cultura do café, que propiciou a ocupação da serra no século XIX, terminou por agravar o desmatamento na década de 1970, na 
tentativa de implantar espécies de maior produtividade. O corte indiscriminado de árvores para servir como lenha, embora venha acontecendo em velocidade menor que no passado, ainda é preocupante. A possibilidade de utilizar tecnologias apropriadas ao ambiente local, identificar nichos de mercado - como, por exemplo, novas culturas, novos consumidores, inclusive na Região Metropolitana e além dela - e adquirir escala de comercialização, estão entre os principais desafios da região para se tornar um produto cultural do ecoturismo.

Observar-se que a escala rudimentar de produtos locais através de engenhos, alambiques, casas de farinha e moageiras de café requer atenção para a infraestrutura de apoio, capacitação e maior divulgação junto aos mercados-alvo, proporcionando numa visão de curto e médio prazo, como dentro de uma perspectiva mais distante, que as potencialidades do desenvolvimento do ecoturismo como segmento estratégico de desenvolvimento territorial, tende a se consolidar na APA da Serra de Baturité.

De posse disto, ao se pensar em um planejamento para ecoturismo na APA, pretende-se também reavivar as memórias, as identidades e o sentimento de pertencimento entre os moradores locais. Compactuando, dessa forma, que a história da APA precisa ser resgatada e preservada a fim de beneficiar a formação do produto ecoturístico.

\section{Conclusão}

A partir das atividades socioeconômicas desenvolvidas ao longo da sua história de ocupação, conclui-se que o principal problema da APA está relacionado à degradação da cobertura vegetal, causando a quebra do equilíbrio natural e desencadeando a intensificação de processos erosivos, entre outros diversos impactos negativos.

No entanto, as ações de Educação Ambiental visam demonstrar a viabilidade prática e fornecer ferramentas técnicas para que as atividades de ecoturismo venham a ser incorporadas pelas comunidades que coexistem com a APA. Dessa forma, por meio de um programa específico de educação e interpretação ambiental é necessário de acordo com as peculiaridades que compõem a comunidade referida.

Em consonância com o exposto em tela, o ecoturismo e a Educação Ambiental devem caminhar em busca de uma gestão integradora que possibilite a proteção socioambiental e cultural dos interesses e valores das comunidades, sendo elas consideradas como parte integrante e não à margem dos benefícios da conservação, sendo a APA da Serra de Baturité uma forte representante dos interesses territoriais frente aos problemas socioambientais e aos conflitos inerentes do atual modo de produção local. 


\section{Referências bibliográficas}

AB'SABER, A. Os Domínios de Natureza no Brasil: potencialidades paisagísticas. São Paulo: Ateliê Editorial, 2003.

ANTUNES, K.G.; COELHO, R.; JOCHEM, T.; A importância da Educação Ambiental em Unidades de Conservação: Experiência do Centro de Referência em Educação Ambiental de Marapendi. Disponível em: <http://www.ivtri.net/sapis/2006/pdf/KarenAntunes.pdf>. Acessado em 18 de jun. de 2016.

BRUGUER, P. Educação Ambiental ou Adestramento Ambiental?. 3.ed. Santa Catarina: Letras Contemporâneas, 1999.

DIAS, G.F. Educação Ambiental: princípios e práticas. 9.ed. São Paulo: Gaia, 2004.

FREY, K. A dimensão político-democrática nas teorias de desenvolvimento sustentável e suas implicações para a gestão local. Revista Ambiente \& Sociedade, ano 4, n. 9, 2. sem. 2001. Disponível em: $<$ http://www.scielo.br/pdf/asoc/n9/16878.pdf>. Acessado em 15 jun 2016.

INSTITUTO BRASILEIRO DO MEIO AMBIENTE E DOS RECURSOS NATURAIS RENOVÁVEIS. (IBAMA) Como o lbama exerce a Educação Ambiental Coordenador geral de Educação Ambiental. Brasília: Ibama, 2002.

JANSEN, G.R.; VIEIRA, R.; KARISCH, R. A Educação Ambiental como resposta à problemática ambiental. Disponível em: $<$ http://www.remea.furg.br/edicoes/vol118/art22v18a14.pdf > . Acessado em $01 \mathrm{de}$ jun. de 2016.

MININI, N. A formação dos professores em Educação Ambiental. In: Textos sobre capacitação em Educação Ambiental. Oficina Panorama da Educação Ambiental, MEC-SEF-DPEF- Coordenação de Educação Ambiental, Brasília, 2000.

OLIVEIRA, J.C.A.; OLIVEIRA FILHO, J.C.A.; PEREIRA, C.S. Meio Ambiente e Planejamento em cidades médias: Discutindo o desenvolvimento Urbano no CratoCeará. Revista da Casa da Geografia de Sobral, Sobral-CE, v. 12, n. 1, p. 59-68, 2010.

PEDRINI, A.G. (org.). Educação Ambiental: reflexões e práticas contemporâneas. 5. ed. Petrópolis, RJ: Vozes, 1997.

Hermógenes Henrique Oliveira Nascimento: Secretaria Estadual do Meio Ambiente do Ceará. Fortaleza, CE, Brasil.

E-Mail: henrique.sampa@gmail.com

Link para o currículo Lattes: http://lattes.cnpq.br/0195752487069939

Data de submissão: 29 de agosto de 2016

Data de recebimento de correções: 17 de setembro de 2016

Data do aceite: 31 de outubro de 2016

Avaliado anonimamente 